\title{
Use of an antigen-capture assay for characterisation of monoclonal antibodies to mycobacterial lipoarabinomannan
}

\author{
SAROJ R. KHANOLKAR, D. B. YOUNG*, P.J. BRENNANt, T. M. BUCHANAN§ and \\ K.P. W. J. MCADAM
}

Department of Clinical Tropical Medicine, London School of Hygiene and Tropical Medicine, Keppel Street, London WCIE 7HT, "MRC Tuberculosis and Related Infections Unit, Hammersmith Hospital, London, †Department of Microbiology, Colorado State University, Fort Collins, CO, USA, §/mmunology Research Laboratory, University of Washington, Seattle, WA, USA, and ||The National Hansen's Disease Center, Carville, $L A, U S A$

\begin{abstract}
Summary. Monoclonal antibodies directed to six separate antigen molecules of Mycobacterium leprae have been tested in an antigen-capture assay based on combined use of polyclonal ("capture") and monoclonal ("detector") antibody reagents. This approach provides a potentially versatile, sensitive and specific assay for detection and relative quantitation of $M$. leprae antigens. Characterisation of monoclonal antibodies to mycobacterial lipoarabinomannan (LAM-B) by the antigen-capture assay indicates that some of the antigenic determinants present on LAM-B from $M$. leprae may be either absent altogether or present at much lower concentrations on the corresponding LAM-B structure from $M$. tuberculosis.
\end{abstract}

\section{Introduction}

Assays for the detection of mycobacterial antigens in tissues and body fluids from infected individuals have a potential role in the diagnosis of disease and in monitoring the effectiveness of chemotherapy. In the case of leprosy, it is important that such assays distinguish between specific antigens of Mycobacterium leprae and the many crossreactive antigens shared by related mycobacteria, such as $M$. tuberculosis, which may often be present at high frequencies in leprosy endemic areas. The availability of mouse monoclonal antibodies (MAbs) directed to individual antigenic determinants of $M$. leprae (Gillis and Buchanan, 1982; Ivanyi et al., 1983; Engers et al., 1985) provides an opportunity for the development of novel antigen detection assays which would have the attractions of being potentially species-specific and of being suitable for monitoring the presence of antigens of defined molecular nature.

Two reports of the use of MAbs for detection of mycobacterial antigens in clinical samples have been published. Chandramuki et al. (1985) used a MAb (ML34) directed to a common carbohydrate determinant of mycobacteria to detect antigen in cerebrospinal fluid from patients with tuberculous

Received 4 Sep. 1987; accepted 12 Jan. 1988 meningitis and Young et al. (1985b) used a MAb (PG2.B8F) in conjunction with immunoblotting to detect the species-specific phenolic glycolipid antigen in sera from patients with lepromatous leprosy. Antigen-capture (or "tandem") assays with MAbs have been used to detect antigens from other infectious agents (Voller, 1980) and development of such assays has been described with the mycobacterial ML34 MAb (Praputpittaya and Ivanyi, 1985 ), and also for the $28-\mathrm{Kda}$ protein of $M$. leprae (Young et al., 1985a) and the 38-Kda protein of $M$. tuberculosis (Young et al., 1986). These assays involve binding of antigen to a solid-phase support through interaction with a "capture" antibody, followed by detection with a second antibody directed to a separate epitope on the same molecule, and can be employed either for an antigen with repeating epitopes (e.g., the ML34 assay) or for an antigen with two spatially separate epitopes, as in the case of the $28-\mathrm{Kda}$ protein. The format of such assays is attractive for detection of antigens in biological samples because the "capture" step allows for an initial partial purification or concentration of the specific antigen. In this paper we report the development of an antigen-capture assay with polyclonal antibody directed to cross-reactive mycobacterial determinants for the "capture" step followed by detection with MAbs directed to $M$. leprae determinants. It can be predicted that this 
strategy should be successful for antigens which contain a mixture of cross reactive and speciesspecific determinants, as has been shown for the $65-\mathrm{Kda}$ and $28-\mathrm{Kda}$ proteins of $M$. leprae (Gillis et al., 1985; Young et al., 1985a).

The antigen-capture assay has been used for analysis of MAb-defined determinants of the mycobacterial lipoarabinomannan-B antigen. Hunter et al. (1986) have recently shown that the previously described arabinomannan antigen of mycobacteria is a partially hydrolysed form of a more complex lipoarabinomannan structure (LAM-B) which contains inositol 1-phosphate, lactate, succinate and fatty acids in addition to arabinose and mannan. The results reported here suggest the presence of species-specific determinants associated with the native LAM-B molecule.

\section{Materials and methods}

\section{Mycobacterial antigens}

Soluble extract from $M$. leprae was obtained from the World Health Organization Leprosy programme through Dr R. J. W. Rees, Clinical Research Centre, London. $M$. tuberculosis $\mathrm{H} 37 \mathrm{Rv}$ was grown for 8 weeks as a surface pellicle on Sauton's medium and a soluble extract was prepared as described previously (Young et al., 1986). The protein concentration in mycobacterial extracts was determined by the method of Lowry et al. (1951), with bovine serum albumin (BSA) as standard. LAM-B was purified from $M$. leprae and $M$. tuberculosis as described previously (Hunter et al., 1986).

\section{Monoclonal antibodies}

The following MAbs were used in the study: $\operatorname{IIE} 9(M$. leprae 65-Kda protein; Gillis and Buchanan, 1982), L12 (M. leprae 65-Kda protein; Britton et al., 1985), SA1.B11H and SA1.D2D ( $M$. leprae 28-Kda protein; Young et al., 1985a), L5 (M. leprae 18-Kda protein; Britton et al., 1985), and MLO4 and MLO6 (M. leprae 35-Kda and 12-Kda proteins; Ivanyi et al., 1983). MAbs SAl.C7F and SAl.C11H were derived from a fusion with spleens from mice immunised with a soluble extract from $M$. leprae as described previously (Young et al., $1985 a$ ). Both antibodies belonged to the $\mathrm{IgG}_{1}$ subclass and recognised subtilisin-resistant determinants. All MAbs were obtained in the form of ascitic fluid and were used in assays at dilutions ranging from 1 in 1000 to 1 in 20000 .

\section{Antigen-capture assay}

Antibody from a rabbit hyperimmunised with $M$. bovis BCG (Dako Ltd, High Wycombe, Bucks) was diluted 1

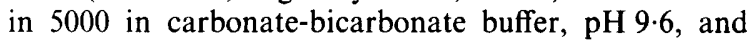
coated overnight at $0-4^{\circ} \mathrm{C}$ to Immulon II microtitration plates (Dynatech Laboratories, Inc., Alexandra, VA). Plates were washed with phosphate-buffered saline, $\mathrm{pH} 7 \cdot 2$, containing Tween $200.05 \% \mathrm{v} / \mathrm{v}$ (PBS-T) and then incubated for $1 \mathrm{~h}$ at room temperature (RT) with BSA $1 \% \mathrm{w} / \mathrm{v}$ in PBS-T (BSA-PBS-T) to block non-specific binding. The BSA was discarded and antigens (mycobacterial extracts or LAM-B) were diluted in $1 \%$ BSA-PBS$T$ and added to the microtitration plate. After incubation for $1 \mathrm{~h}$ at RT, plates were washed three times with PBS$T$ and MAbs diluted in $1 \%$ BSA-PBS-T, were added for $1 \mathrm{~h}$ at RT. Plates were washed again and peroxidaseconjugated affinity-purified goat anti-mouse IgG antibody (Bio Rad, Richmond, CA) diluted 1 in 3000 in BSAPBS-T was added. After $1 \mathrm{~h}$ at RT, plates were washed with PBS-T and colour was developed with tetramethylbenzidine (dihydrochloride) $0.1 \mathrm{mg} / \mathrm{ml}$ in citrate buffer, $\mathrm{pH} 5$, containing hydrogen peroxide $0 \cdot 1 \% \mathrm{v} / \mathrm{v}$. Reactions were stopped by adding sulphuric acid and absorbance was read at $450 \mathrm{~nm}$. Separate control wells without polyclonal antibody, antigen, or MAbs, respectively, were included in each experiment.

\section{Direct binding assay with human sera}

A direct binding assay was performed by diluting LAM-B at different concentrations in carbonate-bicarbonate buffer, $\mathrm{pH} 9.6$ and coating overnight at $0-4{ }^{\circ} \mathrm{C}$ to Immulon II microtitration plates. After washing with PBS-T and blocking as described for the antigen-capture assay, human serum samples (diluted 1 in 300 in BSAPBS-T) were added to the plates and incubated for $1 \mathrm{~h}$ at RT. Plates were washed with PBS-T and peroxidaseconjugated affinity-purified goat anti-human IgG antibody (Sigma Chemical Co., St Louis, MO) was added for $1 \mathrm{~h}$ at RT. Plates were washed again and colour was developed as described above. Results were corrected for any background binding of human serum antibody to uncoated wells of the microtitration plate. Human serum samples consisted of pooled sera from at least six separate donors with lepromatous leprosy, tuberculosis, or without mycobacterial disease.

\section{Results}

\section{Antigen-capture ELISA}

An antigen-capture assay was developed with hyperimmune rabbit anti- $M$. bovis BCG as "capture" antibody followed by detection with a variety of MAbs directed to $M$. leprae. The peroxidaseconjugated affinity-purified anti-mouse antibody used in the assay showed negligible binding to rabbit immunoglobulin and provided a convenient and versatile detection system which avoided the necessity of labelling individual mouse MAbs. Table I shows the results of the antigen-capture ELISA with MAbs IIIE9, L12, MLO4, SA1.B11H, 
SA1.D2D, L5, MLO6, SA1.C11H, and SA1.C7F directed towards $65-\mathrm{Kda}, 35-\mathrm{Kda}, 28-\mathrm{Kda}, 18-\mathrm{Kda}$, $12-\mathrm{Kda}$ protein and LAM-B individual antigen molecules of $M$. leprae. The highest absorbance readings were obtained with antibodies directed to the $65-\mathrm{kda}$ protein and to the LAM-B carbohydrate antigen. The assay was routinely performed in the presence of an excess of BSA $(10 \mathrm{mg} / \mathrm{ml})$ and was thus independent of the purity of the mycobacterial antigen extract used. Preliminary results (data not shown) indicated that normal human serum could be added to the assay with little adverse effect except for a general increase in the background binding of the peroxidase-conjugated antibody reagent.

\section{Monoclonal antibodies to $L A M-B$}

Two of the MAbs listed in table 1 (SA1.C11H and SA1.C7F) were originally characterised as binding to alkali-sensitive, subtilisin-resistant determinants and were subsequently found to recognise the LAM-B antigen purified from $M$. leprae. The high absorbance readings observed with these antibodies in the antigen-capture assay are consistent with the presence of repeating epitopes on the carbohydrate antigen, and addition of purified $M$. leprae LAM-B in the antigen-capture assay showed that sub-nanogram amounts of LAM-B could readily be detected by these MAbs (fig. 1A). SAl.C11H gave consistently higher absorbance readings than $\mathrm{SA} 1 . \mathrm{C} 7 \mathrm{~F}$ indicating either that the former antibody possessed a higher affinity for the
Table I. Screening of MAbs in antigen-capture assay

\begin{tabular}{|c|c|c|c|c|c|c|}
\hline \multirow[b]{2}{*}{$\mathrm{MAb}$} & \multirow{2}{*}{$\begin{array}{l}\text { Antigen } \\
\text { recognised }\end{array}$} & \multicolumn{5}{|c|}{$\begin{array}{c}\text { Absorbance at } 450 \mathrm{~nm} \text { with } \\
M . \text { leprae soluble extract } \\
(\mu \mathrm{g} / \mathrm{ml})\end{array}$} \\
\hline & & 10 & 2 & $0 \cdot 4$ & $0 \cdot 08$ & 0.01 \\
\hline IIIE9 & $65-\mathrm{Kda}$ protein & $1 \cdot 17$ & 0.94 & $0 \cdot 61$ & $0 \cdot 26$ & 0.07 \\
\hline $\mathrm{L} 12$ & $65-\mathrm{Kda}$ protein & $1 \cdot 15$ & 0.91 & 0.63 & 0.23 & 0.07 \\
\hline MLO4 & $35-\mathrm{Kda}$ protein & 0.24 & 0.20 & 0.12 & 0.09 & 0.08 \\
\hline SAl.B11H & $28-\mathrm{Kda}$ protein & 0.22 & $0 \cdot 19$ & 0.06 & 0.08 & 0.05 \\
\hline SA1.D2D & $28-\mathrm{Kda}$ protein & $0 \cdot 30$ & $0 \cdot 28$ & $0 \cdot 14$ & $0 \cdot 10$ & 0.06 \\
\hline L5 & $18-\mathrm{Kda}$ protein & $0 \cdot 18$ & $0 \cdot 15$ & $0 \cdot 13$ & 0 & 0 \\
\hline MLO6 & $12-\mathrm{K}$ da protein & 0.30 & 0.23 & $0 \cdot 20$ & $0 \cdot 12$ & $0 \cdot 12$ \\
\hline SA1.C11H & LAM-B & 1.03 & 0.74 & 0.32 & $0 \cdot 10$ & 0.03 \\
\hline SA1.C7F & LAM-B & 0.65 & $0 \cdot 32$ & $0 \cdot 16$ & 0.02 & 0.02 \\
\hline
\end{tabular}

Different MAbs were used in the antigen-capture assay with $M$. leprae soluble extract as described in the text.

antigen, or that its epitope was present at a higher frequency than that of SA1.C7F on the $M$. leprae LAM-B molecule. When LAM-B from $M$. tuberculosis was used in the assay (fig. 1B), a markedly higher concentration was required to produce absorbance values comparable to that of the $M$. leprae antigen with SA1.C11H (see table II) while no significant recognition of $M$. tuberculosis LAMB by SA1.C7F was found even at high antigen concentrations. Analogous results were obtained when comparing extracts from $M$. leprae or $M$. tuberculosis in the antigen-capture assay with SA1.C11H showing preferential binding to the $M$.
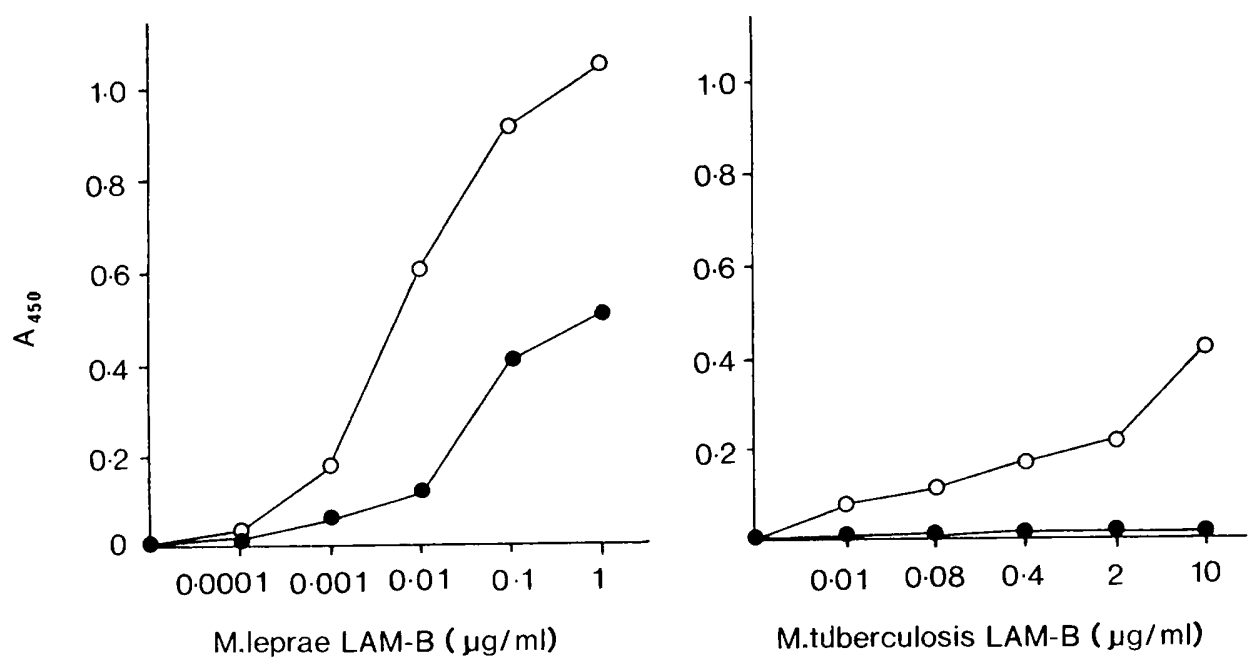

Fig. 1. Antigen-capture assay with purified LAM-B. LAM-B from $M$. leprae or $M$. tuberculosis was added at various concentrations to the antigen-capture assay described in the text and antigen detection was with MAb SA1.C11H (O) or MAb SA1.C7F (O). 
Table II. Quantitative comparison of LAM-B preparations from $M$. leprae and $M$. tuberculosis

\begin{tabular}{l|cc}
\hline & $\begin{array}{c}\text { Antigen concentration }(\mathrm{ng} / \mathrm{ml}) \\
\text { required for } \mathrm{A}_{450} 0 \cdot 2\end{array}$ \\
\cline { 2 - 3 } & $\begin{array}{c}\text { M. leprae } \\
\text { LAM-B }\end{array}$ & $\begin{array}{c}\text { M. tuberculosis } \\
\text { LAM-B }\end{array}$ \\
Antibody & $1 \cdot 2$ & 1200 \\
MAb SA1.C11H & 20 & $>10000$ \\
MAb SA1.C7F & $0 \cdot 3$ & 3 \\
Pooled leprosy sera & $1 \cdot 5$ & 3.5 \\
Pooled tuberculosis sera & & \\
\hline
\end{tabular}

LAM-B purified from $M$. leprae or from $M$. tuberculosis was added at different concentrations to the antigen-capture and the direct binding assay as described in the text. The antigen concentration required to produce an absorbance reading of $0 \cdot 2$ was determined for each of the antibody preparations.

leprae extract and SA1.C7F showing no significant binding to $M$. tuberculosis (figs. 2A and 2B).

\section{Recognition of $L A M-B$ by human sera}

Because of the apparent species-specificity of antigenic determinants on LAM-B, the purified preparations from $M$. leprae and $M$. tuberculosis were each analysed for recognition by antibodies in sera from patients with leprosy or tuberculosis. As shown in fig. 3 , pooled sera from leprosy patients or tuberculosis patients bound strongly to LAM-B prepared from either mycobacterial species while a

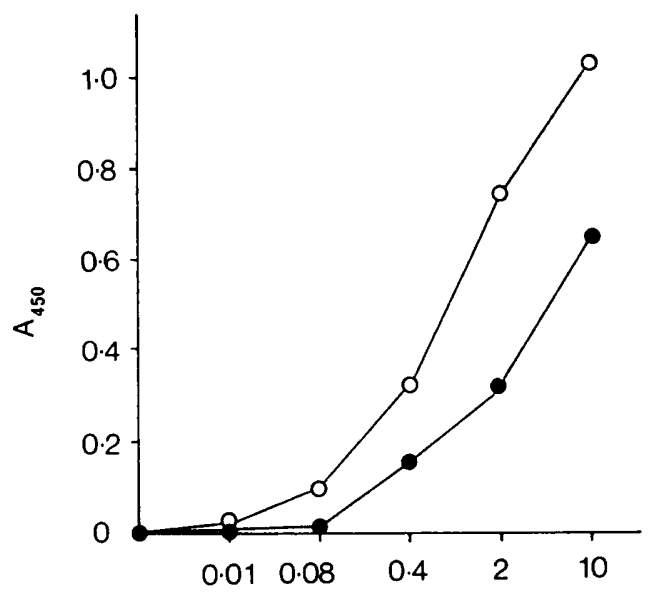

M.leprae extract ( $\mu \mathrm{g}$ protein $/ \mathrm{ml}$ ) serum pool from uninfected individuals showed only a low degree of binding. Some quantitative differences between the two samples were observed with a lower concentration of the $M$. leprae LAM$\mathrm{B}$ producing absorbance values of 0.2 compared to the $M$. tuberculosis LAM-B, particularly in the case of the lepromatous serum pool (table II).

\section{Discussion}

Monoclonal antibodies directed to several antigenic determinants of $M$. leprae were found to function well in an antigen-capture ELISA employing a polyclonal anti-mycobacterial antibody for the "capture" step. This indicates that these antibodies recognise either repeating epitopes (as in the LAM-B molecule) or $M$. leprae-specific epitopes on antigens which also possess separate cross-reactive epitopes. Thus the format of combined use of polyclonal and monoclonal antibodies in such assays appears potentially broadly applicable for monitoring several individual $M$. leprae antigens. While the use of a peroxidase-conjugated secondary antibody for screening a wide variety of MAbs was a convenient aspect of the study described here, further development of such tests with material from human clinical samples has indicated that use of directly conjugated MAbs may be necessary to avoid background binding of the anti-mouse secondary antibody to components in the biological extracts. The antigen capture ELISA provides a highly sensitive assay for antigen

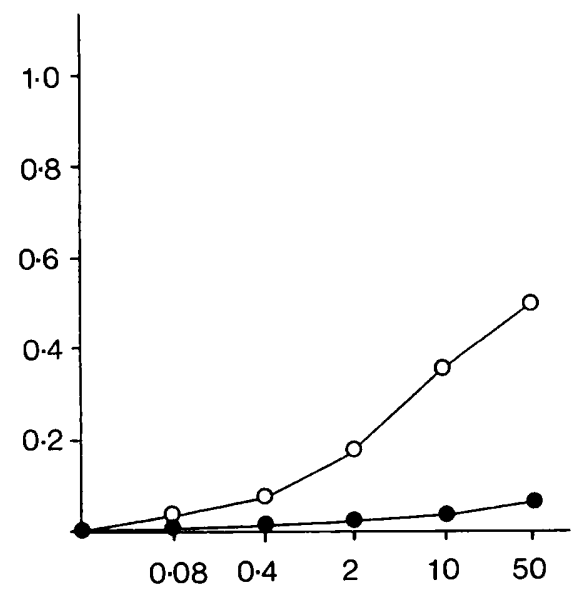

M.tuberculosis extract ( $\mu \mathrm{g}$ protein/ $\mathrm{ml}$ )

Fig. 2. Antigen-capture assay with mycobacterial extracts. Soluble extract from $M$. leprae or $M$. tuberculosis was added at various concentrations to the antigen-capture assay described in the text and antigen detection was with MAb SAl.C11H (O) or MAb SA1.C7F (O). 


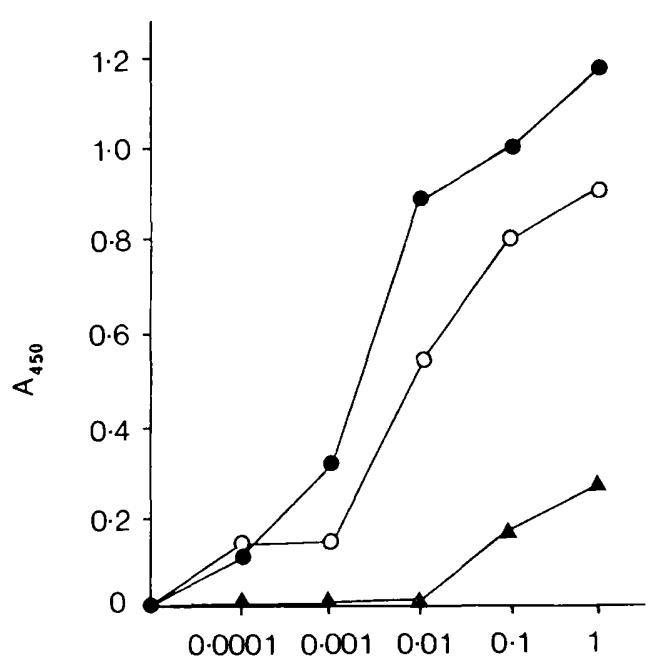

LAM-B (M.leprae)

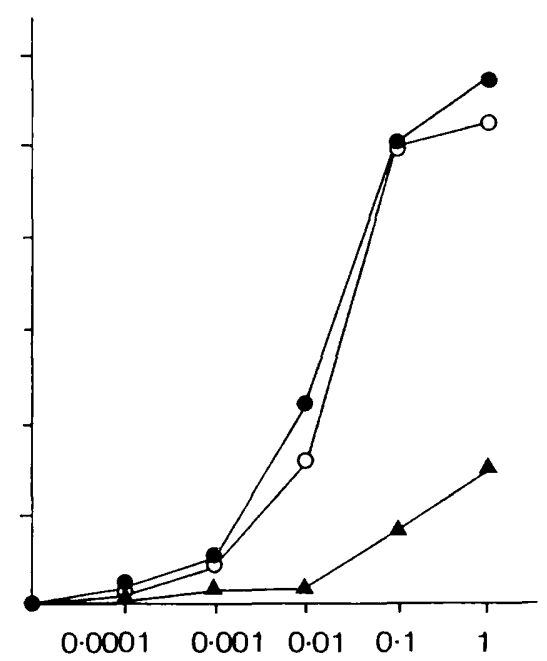

LAM-B (M.tuberculosis)

Fig. 3. Recognition of LAM-B by antibodies in human sera. Various concentrations of LAM-B from $M$. leprae or $M$. tuberculosis were coated to microtitration plates for the direct binding assay described in the text. Assays were then developed with pooled human serum samples ( 1 in 300 dilution) from lepromatous leprosy patients $(-O)$, tuberculosis patients $(O-O)$ or uninfected individuals $(\boldsymbol{\Delta})$.

detection, as was seen with the SA1.C11H assay in which $60 \mathrm{pg}$ of $M$. leprae LAM-B was sufficient to produce an absorbance reading of $0 \cdot 1$. The fact that the antigen-capture assay was not influenced by the presence of other proteins in the test sample, suggests that it may be useful not only for detection but also for relative quantitation of particular determinants in different antigen preparations.

Analysis of purified LAM-B in the antigencapture ELISA with two MAbs demonstrated a marked difference between the antigens purified from $M$. leprae and $M$. tuberculosis. MAb SA1.C11H showed a distinct preference for the $M$. leprae LAM-B whereas SA1.C7F bound well to $M$. leprae LAM-B but did not bind to $M$. tuberculosis LAM-B in the antigen-capture assay. Since it is known that the determinant recognised by each of these antibodies is susceptible to mild alkaline hydrolysis, it can be postulated that the difference in binding has resulted from some partial degradation of the $M$. tuberculosis LAM-B during its purification. Arguments opposed to this explanation are: the observed recognition of both antigens to an almost equal extent by pooled tuberculosis serum; the lack of quantitative differences in the chemical analysis of the two preparations; and the fact that an analogous discrimination between the two mycobacterial species is observed when unfractionated extracts are used in the antigen-capture assay. It seems likely, therefore, that both of the MAbs recognise determinants which occur more frequently on the $M$. leprae LAM-B than on the $M$. tuberculosis LAM-B and, particularly in the case of SA1.C7F, may be useful in specifically detecting the $M$. leprae antigen. Whether this difference in antigenic configuration represents a genotypic difference between $M$. leprae and $M$. tuberculosis, or is a reflection of the different growth conditions (in vivo and in vitro) of the two strains, remains to be answered. The chemical composition of LAMB could allow for a multiplicity of antigenic determinants involving complex succinyl and lactyl modification of sugar residues and further detailed structural analysis of LAM-B will be required to understand fully the origin of the MAb-defined differences in antigenicity. The possible occurrence of species-specific epitopes on complex carbohydrates of mycobacteria is an intriguing possibility with potential biological significance in addition to its importance from the point of view of antigen detection and species identification.

This research was supported by the THELEP component of the UNDT/World Bank/WHO special programme for Research and Training in Tropical Diseases. We thank Drs W. J. Britton and $\mathbf{J}$. Ivanyi for kindly providing the monoclonal antibodies for this study, Dr R. J. W. Rees for helpful discussion, and Susan Dickinson for preparing the manuscript. 


\section{REFERENCES}

Britton W J, Hellqvist L, Basten A, Raison R L 1985 Mycobacterium leprae antigens involved in human immune responses. I. Identification of four antigens by monoclonal antibodies. Journal of Immunology 135: 4171-4177.

Chandramuki A, Allen P R J, Keen M, Ivanyi J 1985 Detection of mycobacterial antigen and antibodies in the cerebrospinal fluid of patients with tuberculous meningitis. Journal of Medical Microbiology 20 : 239-247.

Engers H D et al. 1985 Results of a World Health Organizationsponsored workshop on monoclonal antibodies to Mycobacterium leprae. Infection and Immunity 48: 603-605.

Gillis T P, Buchanan T M 1982 Production and partial characterization of monoclonal antibodies to Mycobacterium leprae. Infection and Immunity 37: 172-178.

Gillis T P, Miller R A, Young D B, Khanolkar S R, Buchanan T M 1985 Immunochemical characterization of a protein associated with Mycobacterium leprae cell wall. Infection and Immunity 49 : 371-377.

Hunter S W, Gaylord H, Brennan P J 1986 Structure and antigenicity of the phosphorylated lipopolysaccharide antigens from the leprosy and tubercle bacilli. Journal of Biological Chemistry 261 : 12345-12351.

Ivanyi J, Sinha S, Aston R, Cussell D, Keen M, Sengupta U 1983 Definition of species specific and cross-reactive antigenic determinants of Mycobacterium leprae using monoclonal antibodies. Clinical and Experimental Immunology 52: 528-536.

Lowry O H, Rosebrough N J, Farr A L, Randall R J 1951 Protein measurement with the folin phenol reagent. Journal of Biological Chemistry 193: 265-275.

Praputpittaya K, Ivanyi J 1985 Detection of an antigen (MY4) common to $M$. tuberculosis and $M$. leprae by "tandem" immunoassay. Journal of Immunological Methods 79: 149157.

Voller A 1980 The use of solid phase isotopic and non-isotopic immunoassays in parasitic diseases with special reference to malaria. International Journal of Nuclear Medicine and Biology $7: 157$.

Young D B, Harnisch J P, Knight J, Buchanan T M $1985 a$ Detection of phenolic glycolipid I in sera from patients with lepromatous leprosy. Journal of Infectious Diseases 152: 1078-1081.

Young D B, Fohn M J, Khanolkar S R, Buchanan T M $1985 b$ Monoclonal antibodies to a $28,000 \mathrm{~mol}$. wt protein antigen of Mycobacterium leprae. Clinical and Experimental Immunology 60: 546-552.

Young D, Kent L, Rees A, Lamb J, Ivanyi J 1986 Immunological activity of a 38-kilodalton protein purified from Mycobacterium tuberculosis. Infection and Immunity 54: 177-183. 